\title{
Five generations of theory-practice tensions: enriching socio-ecological practice research
}

\author{
John Forester ${ }^{1}$ \\ Received: 31 July 2019 / Accepted: 16 August 2019 / Published online: 3 September 2019 \\ (c) Springer Nature Singapore Pte Ltd. 2019
}

\begin{abstract}
The author reviews five generations of views of theory-practice tensions, and explores their implications to socio-ecological practice research. Concerns with wicked problems led to considerations of argumentative planning; questions of resolving conflicting arguments led to process designs of mediated-negotiations. On-going concerns with deliberation reveal the dangers of deliberative malpractices. The pragmatic imperative to act in fluid, complex, and contested settings requires creative and practically situated improvisation.
\end{abstract}

Keywords Theory-practice gaps $\cdot$ Wicked problems $\cdot$ Argumentation $\cdot$ Mediated-negotiations $\cdot$ Deliberative malpractices $\cdot$ Improvisation $\cdot$ Socio-ecological practice research

\section{The challenge of doing socio-ecological practice research and five views of theory- practice tensions}

In this essay, I hope to respond productively to Wei-Ning Xiang's provocative inaugural essay on "Ecopracticology" (Xiang 2019). He argues there, in effect, that doing socioecological practice research confronts at least two major challenges. The first is to build better theory from practice. The second, of course, is to encourage ever better practice on the ground.

These are persisting challenges because too much of our academic theorizing seems to have little to do with practice at all, and too many of our practice studies seem not to advance any theoretical understanding either. The result is that in many of our planning, design and environmental policy-related fields, there seem to be two worlds with little to do with each other-the world of the theorists and the world of the practitioners, and the two seem rarely to meet.

An earlier version of this paper was presented at SEPR 2019, Shanghai-“Socio-Ecological Practice Research: from practice, for practice, beyond practice," June 14-17, 2019, at Tongji University, Shanghai.

John Forester

jff1@cornell.edu

1 Cornell University, Ithaca, USA
That "two-worlds problem" raises the set of issues I wish now to address: How can we better understand the relationships, the gaps and the connections, between knowledge and action, theory and practice in our applied fields - so that we can actually improve socio-ecological practice research and, ultimately, improve socio-ecological practice as well?

With these problems often in mind in my own work, I have tried for many years to develop a theoretically informed, but accessible body of practice research that I have called a "critical pragmatism" (Forester 1999, p. 22; 2017 , pp. 280-295). In what follows, though, I draw a series of lessons from the intellectual history of the fields of urban planning and public policy, and I map out five generations of thought - a development, if not an evolution-of ways that we might understand the uneasy relationships between theory and practice. Each of these five generations has its implications for socio-ecological practice research, implications and lessons that I will summarize by way of conclusion.

The five views of theory-practice tensions to follow are these. The "first generation" view was set out by planning scholars Horst Rittel and Melvin Webber in their classic statement of the so-called wicked problems that confronted professional experts (and the rest of us) with truly perplexing dilemmas. In the face of such wickedness, though, Rittel and Webber did not despair altogether-and they actually pointed toward, but did not really develop, what they called a "second generation" approach, one of argumentative planning. The problems of practice that arose from that approach-problems that were 
evident already in earlier work as different as the dis-jointed incrementalism of political scientist Charles Lindblom and the advocacy planning of Paul Davidoff-led then to what we can consider as a third-generation's approach: the important work of planning scholars Lawrence Susskind and Judith Innes on mediated-negotiations. Such negotiations provided not only a means of reconciling conflicting arguments, but also a strategy of overcoming the apparently devastating theory-practice problems of comprehensive planning. But a far more general problem of theory and practice remained, however, involving the ways that practical judgment—what Wei-Ning Xiang (2016) has characterized as the work of ecophronesis, or ecological practical wisdom-requires deliberatively working with others. Such working across disciplinary boundariesin teams or partnerships, or of sheer necessity-I will argue, involves a fourth-generation's concerns-now, with the practical dangers of what we can call potential deliberative malpractices. Finally, as contexts of region, culture, law and politics vary, the need to act well in unique settings remains, and so a fifth-generation's approach becomes relevant: assessing theory-practice problems under conditions that now demand creatively improvised action.

Along the way, I suggest that we should try not to eliminate, but instead to learn from, insightful views of these theory-practice tensions or gaps as they can inform and help improve our socio-ecological practice research. In that spirit, let me turn to an evolution-perhaps a rough progressionof ways in which we might strive to understand these issues.

\section{The first-generation view: How can we trust experts when we face wicked problems?}

Let us begin with the classical "rationalist" view: if there's a problem to solve, perhaps there's an "expert," a well-trained, well-educated professional who will know how to "solve" our problem. If I ask you, as I ask my students on the first day of classes, "What is the square root of 4?", you might well, as my students do, answer immediately: " 2 !"

"Surely you can do better," I tell them in class.

"Fine," several will say, “ \pm 2 !"

We then note how this problem, and this answer, seem to be well understood and testable-in New York, San Francisco, Shanghai, Johannesburg. The problem of the square root of 4 seems well defined, and the "solution" to it is unambiguous and remarkably context-free of time, space, political sentiment, or cultural practices. The square root of 4 is \pm 2 , full stop.

We then notice in class, of course, how socio-ecological problems and public policy problems more generally are typically NOT those kinds of problems. How to anticipate sea-level rise, how to rebuild after Hurricane Katrina, how to irrigate agricultural lands, how better to educate our children or to provide jobs to the poor, these so-called problems are neither well defined and unambiguous nor are they context-independent. This distinction of types of problems was made famous in the provocative argumentof Horst Rittel and Melvin Webber, professors, respectively, of Architecture and City and Regional Planning at the University of California, Berkeley, USA-in which they distinguished "tame" or "well-behaved" problems from those they called "wicked problems" (cf. Churchman 1967; Rittel and Webber 1973).

Planning and public policy problems, in particular, they argued, were not tame- - because typically they had daunting characteristics like the following:

1. "There is no definitive formulation of a wicked problem" (Rittel and Webber 1973, p. 161);

2. "Wicked problems have no stopping rule" (Ibid., p. 162);

3. "Solutions to wicked problems are not true-or-false, but good-or-bad" (Ibid.);

4. "There is no immediate and no ultimate test of a solution to a wicked problem" (Ibid., p. 163);

5. "Every wicked problem can be considered to be a symptom of another problem," (Ibid., p. 165) and there's more.

No wonder they argued that we should be wary or distrusting of any experts who seemed confident about actually "solving" these kinds of policy problems!

I had the good fortune to be Rittel and Webber's teaching assistant in the required "Planning Theory" course at Berkeley in 1973 and 1974. As Rittel took delight in the logical "dilemmas" of such wicked problems, Webber instead drew a perplexing, but a practical conclusion: "Planning," he liked to say-and not just to tease, but really to provoke his students- "is both impossible and necessary." Webber made this argument-planning is both necessary and impossible - with full ethical irony, knowing that, despite the logical dilemmas of planning, we could not hide in paradox because the world around us, the land and the sea, the wind and the rain, our neighbors and new immigrants and more, all forced us to respond, to act, for better or worse. Choosing not to act in some new way, of course, was also to act-to continue to take this option, not to try something new. We can call that necessity-in the flow of time having to act, never being able to step outside of our on-going historythe "pragmatic imperative of planning." We need to face in some way-directly or evasively, quickly or slowly, in coalition with others or by oneself, with better or worse information - the persistent and undeniable demands of practice that press upon us from the worldly side of the daunting "theory-practice gap." 
Rittel and Webber posed their challenge as a cautionary tale - and as a set of warnings - about the claims of "experts," so their concerns, to "be careful!", were just as much about problem-solvers as they were about problemsolving. If such "wicked" limits of problem-setting and problem-solving theories existed, how could we trust a so-called rational-professional, however well-trainedexpert to define, bound, frame, and really "solve" these sorts of problems appropriately? What additional or external norms, they seemed to lead us to ask, could respond to such internal or endogenous wickedness, such ill-definedpoorly formulated, ethically fraught, and contextually underdetermined-problems?

These questions drove Rittel and Webber to suggest that if a "first-generation" of rationalist, expert-based systems analysis was inevitably threatened by the dilemmas they had identified, then a "second-generation" might allow us to move forward, intellectually and practically. Here's how they put it:

“The systems-approach 'of the first generation' is inadequate for dealing with wicked-problems. Approaches of the 'second generation' should be based on a model of planning as an argumentative process - in the course of which an image of the problem and of the solution emerges gradually among the participants, as a product of incessant judgment, subjected to critical argument" (Rittel and Webber 1973, p. 162; italic by the author). ${ }^{1}$

\section{The second-generation view: learning from debate, the "critical argument" of multiple and diverse experts}

As they articulated this second-generation view of problemsolving, Rittel and Webber made a pragmatic move, one that echoed the philosophical tradition of pragmatists running from Charles Sanders Peirce's philosophy of science through William James's concerns with the "cash value of ideas" to John Dewey's linking of argumentative debate to the vitality of actual democratic discourse (see Bernstein 1971, pp. 165-229; Dewey 1927; James 1907; and Peirce 1958). Intuitively, we can understand their move in the following way.

Let us agree that no one expert is likely to have a monopoly on insight and understanding of the complex problems before us. Surely then we will do better-having to act in the face of uncertainty, conflict, partiality, and change-if we

\footnotetext{
1 Their recognition of judgment seems indebted to Vickers (1968); subsequent work on judgment drawing upon Aristotelian practical wisdom includes Nussbaum (1990), Forester (1999), Flyvbjerg (2004) and Xiang (2016).
}

enable a diverse, interdisciplinary, perhaps representative set of experts to argue and refine their ideas, to model, to practice, roughly, a form of scientific or ethical debate, so that from their intelligence and diligence, from their insight and sensitivity, better ideas for problem-solving might emerge. ${ }^{2}$

Notice that in this "argumentative model," our focus shifts-from a relatively solo "expert" toward a more pluralistic, diverse array of participants who might produce, through well-managed debate and argumentation, better substantive ideas about problem-solving. ${ }^{3}$ The appeal here is to meet the ignorance or partiality or limits of one expert with the complementary insight, attention, and proposals of others. ${ }^{4}$ We see this kind of pragmatic move in our everyday lives all the time: If we are stuck or perplexed or unsure about how best to go on, perhaps we can draw upon the insight, advice or experience from others, perhaps several others.

This move from the presumed centrality and yet limits of expert knowledge to a more distributed intelligence had widespread echoes in later appeals to networking, adaptive management, and even discussions of resilience. The appeal to argumentation gives up the idea that there's a single right theoretical answer to be found by a centralized planning intelligence, and instead, now, the responsibility for formulating what is to be done will rest no longer on one professional staff, one tight group of experts, but on a networked or engaged set of participants who critically bring their specialized knowledge and interests to bear. ${ }^{5}$

Political scientist Charles Lindblom had anticipated a political version of this move in his powerful attack upon comprehensive planning that was brilliantly titled, "The

\footnotetext{
${ }^{2}$ Practice studies in sociology and political science had long paid attention to the significance of language use; for a setting out of "the argumentative turn in policy analysis and planning," see the essays collected in Fischer and Forester (1993) showing how that debate could take practical forms; Dewey (1927, Chapter 6) showed how it might improve ideas scientifically and politically, influencing Habermas's ideas about "discourse" accordingly (see Bernstein 1971, Part 3; 1976, pp. 171-235).

${ }^{3}$ For Dewey, whose pragmatist account of "truth" was "warranted assertibility" in a community of enquirers (Dewey 1941, pp. 169186), and in the work of Popper (2002), emphasizing the significance of the on-going, ever more refined play of "conjecture and refutation," such argumentation fueled scientific advance. In particular, in public policy fields the play of diverse argumentation resonated with aspirations to achieve more democratic, participatory processes (e.g., Marris and Rein 1967, Epilogue).

${ }^{4}$ Brian Head (2018, p. 13) writes, "In confronting the intractability of complex policy challenges, the 'wicked' problem perspective in public policy entails a call for governments to embrace stakeholder pluralism, acknowledge the limits of current knowledge, foster learning processes and develop procedural reforms to make policymaking more open and transparent."

5 For a recent appeal to the significance of networks, for example, see Paolisso et al. (2019).
} 
Science of Muddling Through" (1959). In his defense of a dis-jointed incrementalism, he had argued, if rather weakly, for the role of watch-dogs who might speak up for particular interests-the less well organized, the poor, the black and the brown - who lay beyond the periphery of decisionmakers' attention. If any given decision-maker could not rationally and realistically be expected to take all affected interests into account, perhaps some form of "watch-dogs" could help.

Where Lindblom had put administrative decision-makers in the foreground and the watch-dogs in the background, the civil rights lawyer and housing advocate Paul Davidoff inverted that picture. Davidoff's argument for "advocacy planning" put the watch-dogs, his advocacy planners, instead into the foreground to prevent the illegitimate exclusion of deserving interests by inevitably partial and informationstarved decision-makers (Davidoff 1965). Advocacy planning was a democratizing, if quasi-judicial, solution. If any central planning staff faced overwhelming difficulties in making a comprehensive plan, as Lindblom had argued, then it would surely be better, Davidoff argued in turn, if poor and less well-organized neighborhoods had their own advocates, their own distributed planners, presenting what would then be so-called plural plans. Davidoff's proposal resonated with his own legal training: Rather than have one planning expert render a solution, let's have plural plans presented in a lively, critical debate about the welfare of the city, and let's have the Planning Commission and the City Council decide then what to do, based on the diverse and competing arguments put forward by these "advocacy planners."

In the first generation, Webber and Rittel had focused on the limits of expert knowledge in the face of wicked problems that seemed to paralyze problem-solving practice. In the second-generation view of the gap between theory and practice, between knowing and doing, the appeal to fostering and learning from distributed, diverse arguments, included now a broadening out of responsibility by engaging multiple inputs in a form of debate-in which critical argument, local knowledge, and diverse capacities might all be brought into play. ${ }^{6}$ The gap between theory and practice has been narrowed here, but now a crucial missing piece calls for attention: How can we move from robust argument, through the conflict that it implies, to practical decision-making? We can grant that argumentation and debate might sharpen ideas and enrich initial problem-solving proposals, but how could all of these debaters and all of these advocates ever come to make practical decisions together? Argumentation and distributed intelligence promised better theoretical focus, perhaps enhanced relevance, insight and even efficiency, but it

\footnotetext{
${ }^{6}$ See the diverse essays on policy analysis seen as argumentation in Fischer and Forester (1993).
}

would take a third-generation view to address how practical decisions could actually result.

\section{The third-generation view: forms of negotiation matter, and so can those of mediation}

In the 1960s, 1970s, and 1980s in the USA - parallel to Rittel and Webber's provocative argument about wicked problems and their suggestion of an argumentative planning-a rich and diverse literature developed surrounding the problems and possibilities of what we might call "participatory planning." For students, scholars, and practitioners interested in social justice in planning and public policy fields, Sherry Arnstein's "Ladder of citizen participation" (Arnstein 1969, pp. 216-224) had presented an on-going challenge: how could participatory, representative planning processes be more than empty promises of influence, more than political rituals of "we participate, but they really decide" ? Furthermore, how could participatory processes integrate and not de-value the contributions of trained expertise?

These questions were powerfully addressed by two decades of work pioneered by Lawrence Susskind of Massachusetts Institute of Technology (MIT) (e.g., Susskind and Cruickshank 1987; Susskind et al. 1999; also see Forester 2013). Then, in the mid-1990s, Judith Innes of the University of California at Berkeley drew upon Susskind's work in a quietly revolutionary reframing of the theory-practice gap.

Innes powerfully refuted Alan Altshuler's classic critique that comprehensive planning was an exercise in theoretical impossibility and futility (Innes 1996). Innes drew upon diverse cases of environmental disputes - over water, land use, and transportation, for example - to show, in effect, how a "second-generation" argumentative model could now be transformed to take operational form in a third-generation's model of multi-stakeholder mediated-negotiations.

Diverse representatives of affected populations could convene; they could put forward their best arguments, their local knowledge, and their competing proposals for what ought to be done. Further, with the expertise of trained mediators, these stakeholders could not just argue but actually negotiate now to craft agreements on practical solutions. ${ }^{7}$

Innes wrote, for example, "In several cases, stakeholders representing opposing views jointly selected a set of experts, who then pursued internal agreement on scientific questions, to be accepted by the larger group" (Innes 1996, p.468). Employing such joint fact finding, these

\footnotetext{
7 For extensive treatments of such expertise-rich, mediated negotiations, see Susskind (1987), Susskind et al. (1999), Innes and Booher (2010), Forester (2009, 2013), Matsuura and Schenk (2017).
} 
mediated-negotiation processes could integrate the best available science and expertise into multi-stakeholder, participatory processes. This strategy, Innes argued, met Altshuler's objections to planning done by a restricted group of experts (the first-generation's objections), and it also solved decision-making problems (the second-generation's objections).

Like Susskind, Innes argued that mediated-negotiations enabled diverse parties to make consent-based, legitimate decisions. These decisions sought wisdom by leveraging the best available science in the contexts at hand; they promoted efficiency by maximizing joint gains across the stakeholders' differing interest priorities. ${ }^{8}$

As importantly here, the mediators were neither judges nor decision-makers: for mediators do not make agreements any more than midwives make babies (Forester 2009, p. 175). ${ }^{9}$ Like midwives, mediators work to help disputing parties deliver healthy results; but the mediators are not the parents - they do not produce or own the negotiated agreements. The parties - the stakeholders-own their negotiated agreements.

Such third-generation-mediated processes address our prior problems of legitimacy, diffuse expertise, and decisionmaking-now as an orchestrated application of collective intelligence (Sclavi 2018). Here the work of ecophronesis (Xiang 2016; see also Forester 2018a) takes on a deliberative process design. Diverse parties present their histories and their theories: They make their arguments reflecting their hopes and fears. They listen to invited experts; they invent and refine options in the particular contexts at hand; and they negotiate to seek mutual gains. ${ }^{10}$ They give up building (or preserving) here, in this particular place, to do better instead by building or preserving there, in that other place.

But this leads us to a more general question of the fourth generation: What happens in deliberative practices in the absence of mediated-negotiations? In the fourth-generation's

\footnotetext{
${ }^{8}$ Crucially for our argument here, Susskind showed how mediated processes went beyond reducing "participation" to either mere "voice" or argument alone without a way of reconciling differences (Forester 2013, pp. 261-296).

9 This is no longer an appeal to diverse debaters with a vague decision-making function in the mists. Although they are not judges, mediators make a substantial, practical difference: They enable the diverse and conflicting parties to listen to one another, to learn about the problems at hand from one another and from invited experts, and to subsequently invent and propose options that can work for them, including for represented future generations too. For sustained case examples, see Forester (2013).

10 "Even proponents of evidence-based policy making have recently begun to emphasize the need for participants in scientific debates to exchange their views 'on data, model settings, and system boundaries and try to reach a joint interpretation of the evidence' (Kay 2011: 239). The result of this process, Kay emphasizes, is 'negotiated knowledge"” (Daviter 2019, p. 71).
}

view, we face more general problems of deliberation without mediation to address socio-ecological practice (research) and ecophronesis among affected actors: Here we need to work on problems with others-and if we ignore "working relationships," we risk deliberative malpractices.

\section{The fourth-generation view: infrastructural elements of working with others and subtle dangers of deliberative "malpractices"}

Even without the assistance of skilled third-party mediators, interconnected stakeholders still have to deal with each other and engage "together" in problem-solving work. That will require not only the reflective practices of individuals' learning - the focus of Donald Schön's Reflective Practitioner (1983) - but also the interactive and deliberative practices of working together with others (Forester 1999, Chapter 5; Forester et al. 2019).

This deliberative work will involve not only the firstgeneration's inevitably selective experts, but others tooresidents, neighbors, business interests, advocates, politicians-and it will involve not just the second-generation's argumentation but also the third-generation's give-and-take of negotiations-but now lacking mediators' assistance and active intervention. After Hurricane Katrina, for example, planners and community leaders in New Orleans, USA, had to work with remaining residents, with displaced residents, with struggling businesses, with local, state and federal officials, with NGOs, and so on.

These common imperatives of deliberating or working together bring us now to a fourth-generation view of theory and practice tensions. I can make this case best by reporting a series of intriguing classroom experiments that I have done in the last few years.

I have long been worried that Schön's social-psychological framing of "reflective practice" (italic by the author) too easily ignored very real practical, moral and political, and, not least of all, theoretically compelling issues of "deliberative practice," the on-going efforts of learning and working with others.

I had often explored with my students the practical work of "listening." In listening well to others, of course, we attend not just to the literal words we hear but to the persons speaking. We can learn from what they do not say, or from how they emphasize something, or speak in jest, or in frustration or in anger. In all these ways we may learn, and so we can say that listening has acquisitive properties. But once I asked my students to consider not this acquisitive aspect of listening, but its performative or generative face.

"What difference has it made to you," I asked them to write out briefly, "when someone else has really been 
listening to you? You've had something to say that mattered, and someone else has not just been politely hearing you out, but they've really been listening-what difference did that make to you?"

I asked this question first a few years ago in a second year, undergraduate class in Urban and Regional Studies at Cornell University, USA. The results were quite surprising and interesting, I thought, but maybe they just reflected the views of a quite biased sample: a young, maturing group of college sophomores. The initial results were discussed first in small groups and then presented to the entire class. The differences made, the students reported, were that they were:

respected; taken seriously; recognized; safe; included; more likely to reciprocate; supported; cared for...

Here were practical impacts that my students identified as the results of another person's really listening to them. I had asked "what differences" had been made, and their responses, then, began to reveal "the pragmatics of listening." 11 But then I realized that these responses indicated much more than that, too.

These students had begun here to identify the qualities of what we might call, "the moral infrastructure of deliberation." Depending upon the variably attentive work of listening, they had suggested, deliberators-people working together-could actually produce more or less respect or disrespect, acknowledgment or humiliation, recognition or dismissal, inclusion or exclusion, sense of safety or danger. Hardly one of these qualities of relationship, these qualities of deliberative interaction, seemed really considered or accounted for in Schön's theory of reflective practice!

But these qualities-being disrespected or humiliated or dismissed or excluded, or their opposites-obviously seemed to matter practically in problem-solving, planning, or public policy practices. So here, it seemed, I had stumbled onto a significant theory-practice gap! Experts, for example, could be technically competent and self-assured but

\footnotetext{
${ }^{11} \mathrm{I}$ had not asked about any ideals, hopes or principles. I had asked the pragmatist's 'so what?' question: What differences had it ever made when another really listened? On the pragmatics of speech, see Searle (1970) and Austin (1961). Stanley Cavell suggested the moral character of these pragmatics when he wrote, "[S]omething does follow from the fact that a term is used in its usual way; it entitles you (or, using the term, you entitle others) to make certain inferences, draw certain conclusions. (This is part of what you say when you say that you are talking about the logic of ordinary language.) Learning what these implications are is part of learning the language... We are therefore exactly as responsible for the specific implications of our utterances as we are for their explicit factual claims. And there can no more be some general procedure for securing that what one implies is appropriate than there can be for determining that what one says is true. Misnaming and misdescribing are not the only mistakes we can make in talking. Nor is lying its only immorality." (Cavell 1969, pp. 11-12).
}

nevertheless disrespect community members, and cooperation could well suffer. Officials preoccupied with their own agendas might seem dismissive — of experts and community members alike - and resistance might ensue, and so on.

But these results were just from college students, I thought. Then 2 years later, I addressed an MIT (Massachusetts Institute of Technology, USA) symposium of midcareer professionals—graduates of the "Special Program in Urban and Regional Studies" program (the SPURS program) who worked in ministries and planning organizations around the world. In the middle of my presentation on the workshop's theme-extending Schön's work on reflective practice-I asked them to take out their smart phones, to address a message to me, and, in the subject line, to tell me in a few words what difference it had ever made to them when a colleague had really listened. I soon received 30 -odd responses, and here came yet another surprise: Their responses were virtually identical to those of my younger students at Cornell University, with one exception: The mid-career professionals added in, "empowered," as well—meaning practically, here, that they might be even more able to act.

Now, I thought, I really had been too dismissive of my own students' youthfulness. A far more diverse, multinational group of accomplished professionals had corroborated the students' responses. Ready now to take these two sets of suggestions more seriously, I repeated this "experiment" in several more classes, at New York University, USA, and the University of Amsterdam, the Netherlands, too-with strikingly similar results. I began, also, to explore the related question, "What difference did it make to you when another has NOT been listening well?" Here, less surprisingly but still instructively, responses indicated that disrespect could lead to anger, dismissal could lead to resentment, threats could lead to defensiveness, being rendered invisible could lead to distrust and withdrawal, to take several examples. ${ }^{12}$

These findings, I believe, teach us about a fourth-generation's view of gaps between theory and practice. If our problem-solvers are so highly trained as scientists or economists that they cannot work with people different from themselves, we might well have fine theorists who are nevertheless incompetent practitioners. How often have we heard complaints that various "experts" have spoken in languages that others could not understand, or that they failed to pay attention to local concerns? But now, taking a more pragmatic view, we see new problems: it's not the experts' theory

\footnotetext{
12 These simple empirical results, I believe, provide a fresh view of a precarious moral infrastructure of working relationships in planning and socio-ecological practices more generally. These suggestions point out contingencies and practical vulnerabilities not only of deliberative encounters-wherever actors must work together-but perhaps of community-building efforts more generally (Forester 2018b).
} 
alone that's problematic, it's their practice, their behavior: their disrespect, their humiliation of others, their being seen as threatening, their apparent lack of concern if not empathy, and more-all these not captured in their theories at hand.

"Working with others," then, is apparently not as simple as it sounds, and here we have unearthed issues of practical ethics in the form of deliberative malpractices. These include, but are not limited to, contingencies of respect, recognition, reciprocity, and care, or their practical opposites and the reactions they can engender-disrespect and anger, humiliation and resentment, arrogance and lack of cooperation. These concepts are less familiar to natural and social scientists than to moral philosophers. But my research suggests that socio-ecological practice studies will remain more superficial than they need to be if they ignore the practical and moral risks of the deliberative malpractices revealed by this fourth-generation view (De Leo and Forester 2017; Forester 2018b).

\section{The fifth-generation view: theory and practice engage as practitioners improvise in uniquely particular situations}

Here we have to address the possibilities of improvisation, acting responsively, responsibly and creatively in fluid, uncertain and ambiguous, even contested contexts (Barrett 2012; Laws and Forester 2015, Chapter 1). My suggestion here is deceptively simple. To improvise well in practice, as I have argued in a recent analysis of ecophronesis ("ecological practical wisdom") (Forester 2018a), actors-who are always concerned with "What might work now?"-must interweave three strands of practical questions-questions that they must ask over time as contexts shift and situations change:

What is important to attend to here?

What do and don't we know, and so what do we need to learn?

How can we act, what can we negotiate so that we can act now?

To both ask and answer these three sets of questions in on-going work over time takes shape in the form of three intertwined processes that provide, as the strands of a triple helix, a deep structure of practical improvisation.

The first of these processes involves the inquiring work of dialog and conversation to establish meaning, interests, and significance. For example, in our post-Katrina project in New Orleans, USA, this meant doing extensive interviews with residents, officials, community organization leaders-what were their priorities, their hopes and fears, their concerns and commitments? (Reardon and Forester 2016, pp. 52-65)

The second of these processes involves the inquiring work of debate, research and leveraging expertise to clarify what's known about the cases at hand. In New Orleans, this meant extensive spatial and geo-physical mapping of elevations, vulnerabilities, and storm damage.

The third of these processes involves no less significant inquiring work of negotiation and multi-stakeholder mediated-negotiations to determine what can now be done. In New Orleans, this meant managing a partnership with ACORN [Association of Community Organizations for Reform Now] Housing-a non-profit affordable housing development organization-to lobby local politicians and present an evidence-based plan to officials and the press alike that produced a public commitment from the City for \$135 million for the Ninth Ward (Reardon and Forester 2016, pp. 21-51, pp. 81-91).

Why are these three questions-and these three corresponding processes of on-going inquiry - pragmatically important? Without attention to conversations about significance, we will solve the wrong problems; without attention to research and expertise, we risk acting stupidly; and not least of all, without attention to negotiating possibilities, we risk talking, talking, talking and doing nothing morehardly acting in new and effective ways at all.

My suggestion of a fifth-generation view could thus be put this way: We should not attempt to eliminate the tensions or gaps between theory and practice, but perhaps we should think about trying to make them work for us, serve us, in socio-ecological practice. To do that in an accessible, simple, yet deep way, I suggest, we must keep the tensions alive between the realms of what matters, what we know, and what we can do, with the associated questions they each involve. In this way, we might not lose sight of value questions, scientific questions, and activist questions at any given time. If we have to live with continuing tensions between our theorizing and our applied practices, let us try to do that by always integrating these three sets of performed questionsso that we can act, on what matters, with the best knowledge we might have. ${ }^{13}$

\footnotetext{
13 These three questions and three strands of inquiry, question and answer, inquiry and action, represent clusters of both theoretical and practical concerns. The first evolving process is squarely about questions of value and stakeholders' interests, preferences and evolving preference, and related questions of good, justice, beauty and other ideals. The second on-going process is squarely about science, research, inquiry, investigation, scholarship, the pragmatic but not fully rationalist sense that stakeholders can learn more about what concerns them. The third strand of the triple helix, the third process, is squarely about issues of action, singly and together, issues of stakeholders' negotiation, advocacy, coalition building, and decision-making.
} 
Table 1 Five generations' views of theory-practice tensions and their implications for socio-ecological practice research (SEPR)

\begin{tabular}{lll}
\hline Views & Focus & Implications for SEPR \\
\hline First-generation & Wicked problems & Study expert accountability and autonomy \\
Second-generation & Argumentative planning & Study plural voices, conflicting arguments, diverse influence \\
Third-generation & Mediated multi-stakeholder negotiations & Study negotiation of differences, roles of intermediaries \\
Fourth-generation & Deliberation's moral infrastructure & Study deliberative practices and malpractices \\
Fifth-generation & Improvisation in unique, changing settings & $\begin{array}{c}\text { Study how what matters, what's known, and what's negotia- } \\
\text { ble have been explored or ignored }\end{array}$ \\
\hline
\end{tabular}

\section{Enriching socio-ecological practice research}

To conclude, these five generations of views of theory-practice relationships suggest distinct analytic implications for enriching socio-ecological practice research (see Table 1).

First, if we ignore the wickedness and complexity of practice problems, our research will miss the disciplinary and moral partialities of experts' practices-and we will risk encouraging experts' autonomy at the risk of undermining experts' accountability;

Second, if we focus on the interplay of interdisciplinary arguments, perhaps via networking to engage a distributed intelligence, we risk attending to diverse "voices of stakeholders" without carefully assessing questions of those stakeholders' uneven access to information or media, their agenda setting and the available decision-making mechanisms at hand for reconciling their differences by negotiating conflicts-that is, diverse issues of power;

Third, if we focus on issues of decision-making, and the related dispute and conflict resolution processes, we will still need to attend to the issues of more or less skillful thirdparty mediating or managing roles, as well as to issues of representation and the adequacy of joint fact-finding efforts.

Fourth, more generally, where problem-solving calls for deliberations that involve transdisciplinary, multistakeholder teams, partnerships, and coalitions, we need to attend to the possibilities and precariousness of capacity- or community-building - for these deliberations might nurture or, through deliberative malpractices, undermine working relationships-cultivating respect or disrespect, recognition or humiliation, mutuality or withdrawal, and so on, in the process.

Fifth, in the face of complexity, we can anticipate that socio-ecological practices will have to be improvisational, requiring careful attention to three distinct processes of (1) formulating significance or value (or attending to irrelevant issues), (2) assessing what is known and yet to be studied (or acting without available expertise), and (3) negotiating what can be done (or failing to act well at all).

Thinking more carefully about these issues of the interplay of theory and practice — as revealed through these five generations of perspectives-might help us to do still better socio-ecological practice research and, perhaps, to improve such practice itself as well.

\section{References}

Arnstein S (1969) A ladder of citizen participation. Am Inst Plan J 35(4):216-224

Austin J (1961) Performative utterances. In: Austin J (ed) Philosophical papers. Oxford University Press, Oxford, pp 220-239

Barrett F (2012) Yes to the Mess. Harvard Business School Press, Cambridge

Bernstein R (1971) Praxis and action. University of Pennsylvania Press, Philadelphia

Bernstein RJ (1976) The restructuring of social and political theory. University of Pennsylvania Press, Philadelphia

Cavell S (1969) Must we mean what we say?. Cambridge University Press, Cambridge

Churchman CW (1967) Wicked problems. Manag Sci 14(4):B141-B142

Davidoff P (1965) Advocacy and pluralism in planning. J Am Inst Plan 31:103-114

Daviter F (2019) Policy analysis in the face of complexity: What kind of knowledge to tackle wicked problems? Public Policy Adm V34(1):62-82

De Leo D, Forester J (2017) Reimagining planning as moving from reflective to deliberative practice. Plan Theory Pract 18(2):202-216

Dewey J (1927) The public and its problems. Swallow Press, New York

Dewey J (1941) Propositions, warranted assertibility, and truth. J Philos 38(7):169-186. https://doi.org/10.2307/2017978

Fischer F, Forester J (eds) (1993) The argumentative turn in policy analysis and planning. Duke University Press, Chapel Hill

Flyvbjerg B (2004) Phronetic planning research: theoretical and methodological reflections. Plan Theory Pract 5(3):283-306

Forester J (1999) The deliberative practitioner. MIT Press, Cambridge

Forester J (2009) Dealing with differences: dramas of mediating public disputes. Oxford University Press, New York

Forester J (2013) Planning in the face of conflict. American Planning Association Press, Chicago

Forester J (2017) The evolution of critical pragmatism. In: Haselsberger $\mathrm{T}$ (ed) Encounters in planning thought. Routledge, New York, pp 280-295

Forester J (2018a) Ecological wisdom through deliberative improvisation. J Urban Manag 8(1):12-19

Forester (2018b) On the micro-foundations of community-building: learning from mistakes and deliberative malpractices. Presented at the Association of Collegiate Schools of Planning conference, Buffalo, NY 
Forester J, Kuitenbrouwer M, Laws D (2019) Enacting reflective and deliberative practices in action research. Policy Stud 40(5):456475. https://doi.org/10.1080/01442872.2019.1618445

Head BW (2018) Forty years of wicked problems literature: forging closer links to policy studies. Policy Soc. https://doi. org/10.1080/14494035.2018.1488797

Innes J (1996) Planning through consensus building: a new view of the comprehensive planning ideal. J Am Plan Assoc 62(4):460-472

Innes J, Booher D (2010) Planning with complexity. Routledge, New York

James W (1907) Pragmatism. Longman Green and Co, New York

Kay A (2011) Evidence-based policy-making: the elusive search for rational public administration. Aust J Public Adm 70:236-245

Laws D, Forester J (eds) (2015) Conflict, improvisation, governance. Routledge, New York

Lindblom C (1959) The science of muddling through. Public Adm Rev 19(2):79-88

Marris P, Rein M (1967) Dilemmas of social reform: poverty and community action in the United States. Routledge, New York

Matsuura M, Schenk T (eds) (2017) Joint fact-finding in urban planning and environmental disputes. Routledge/Earthscan, New York

Nussbaum M (1990) Love's Knowledge. Oxford, New York

Paolisso M, Prell C, Johnson KJ, Needelman B, Khan IMP, Hubacek K (2019) Enhancing socio-ecological resilience in coastal regions through collaborative science, knowledge exchange and social networks: a case study of the Deal Island Peninsula, USA. Socio-Ecol Pract Res 1(2):1-15. https://doi.org/10.1007/s42532-019-00010-w

Peirce CS (1958) How to make our ideas clear. In: Wiener PP, Peirce CS (eds) Selected writings. Dover, New York

Popper K (2002) Conjectures and refutations: the growth of scientific knowledge. Routledge, New York

Reardon KM, Forester J (eds) (2016) Rebuilding community after Katrina: transformative education in the New Orleans planning initiative. Temple University Press, Philadelphia

Rittel H, Webber M (1973) Dilemmas in a general theory of planning. Policy Sci 4:155-159
Schön D (1983) The reflective practitioner. Basic Books, New York Sclavi M (2018) Working with passion, anger and creativity. In: De Leo D, Forester J (eds) Reimagining planning: how italian urban planners are changing planning practices. INU Press, Rome

Searle J (1970) Speech acts. Cambridge University Press, Cambridge Susskind L, Cruickshank J (1987) Breaking the impasse. Basic Books, New York

Susskind L, McKearnan S, Larmer JT (eds) (1999) The consensus building handbook. Sage, Thousand Oaks

Vickers Sir Geoffrey (1968) The art of judgment. Metheun, London

Xiang W-N (2016) Ecophronesis: the ecological practical wisdom for and from ecological practice. Landsc Urban Plan 155:53-60

Xiang W-N (2019) Ecopracticology: the study of socio-ecological practice. Socio Ecol Pract Res 1(1):7-14

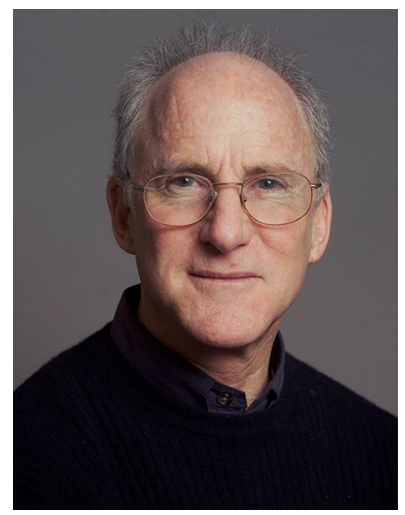

John Forester is a professor of City and Regional Planning at Cornell University, USA. He has explored issues of power, deliberation, and dispute resolution in, respectively, Planning in the face of power (1989), The deliberative practitioner (1999), and Dealing with differences (2009). His current research involves practical judgment and improvisation in complex cases. 